\title{
Emerging approaches to pre-hospital hemorrhage control: a narrative review
}

\author{
Leila Jamal ${ }^{1}$, Aman Saini ${ }^{2}$, Keith Quencer ${ }^{3}$, Izzet Altun ${ }^{1}$, Hassan Albadawi ${ }^{1}$, Aditya Khurana ${ }^{4}$, \\ Sailendra Naidu ${ }^{1}$, Indravadan Patel ${ }^{1}$, Sadeer Alzubaidi ${ }^{1}$, Rahmi Oklu ${ }^{1}$ \\ ${ }^{1}$ Division of Vascular \& Interventional Radiology, Laboratory for Patient Inspired Engineering, Mayo Clinic, Phoenix, AZ, USA; ${ }^{2}$ Department of \\ Radiology, University of Missouri Kansas City, Kansas City, Missouri, USA; ${ }^{3}$ Department of Radiology, University of Utah, Salt Lake City, Utah, \\ USA; ${ }^{4}$ Mayo Clinic Alix School of Medicine, Scottsdale, AZ, USA \\ Contributions: (I) Conception and design: L Jamal, R Oklu; (II) Administrative support: R Oklu; (III) Provision of study materials or patients: R Oklu; \\ (IV) Collection and assembly of data: L Jamal, R Oklu; (V) Data analysis and interpretation: L Jamal, R Oklu; (VI) Manuscript writing: All authors; \\ (VII) Final approval of manuscript: All authors. \\ Correspondence to: Rahmi Oklu, MD, PhD. 13208 E Shea Blvd, Scottsdale, AZ 85259, USA. Email: Oklu.Rahmi@mayo.edu.
}

\begin{abstract}
In the United States, trauma claims the lives of over 150,000 civilians each year. In military settings, trauma and exsanguination result in $50 \%$ of combat related deaths. The majority of these deaths result from uncontrolled non-compressible hemorrhage. Non-compressible hemorrhage often results from deep vascular injuries within the torso, however can also occur secondary to penetrating injuries that involve the extremities. Given the high mortality rates for non-compressible hemorrhage, rapid and effective management of patients suffering from hemorrhage is essential to good patient outcomes. Consequently, there has been increasing interest in solutions for point-of-injury hemorrhage control in trauma and military medicine. Undoubtedly there is a great need for prehospital hemostatic interventions that can be deployed by trained and untrained personnel. Since 2001, various hemostatic agents have been developed, each with its advantages based upon the type and severity of injury, wound size, wound location, accessibility to injury site, and the coagulation status of the patient. These agents are often used in the military setting as a temporizing measure prior to definitive therapy and include techniques such as resuscitative endovascular balloon occlusion of the aorta (REBOA) and bioengineered agents including ResQFoam, RevMedx's XSTAT, Tranexamic acid (TXA), and QuikClot Combat Gauze (QCG). Here, we review the indications, composition, technique, efficacy, and outcomes of these hemostatic agents.
\end{abstract}

Keywords: Trauma hemorrhage; hemostatic agents; minimally-invasive intervention

Submitted Nov 05, 2020. Accepted for publication Jun 18, 2021.

doi: $10.21037 / \mathrm{atm}-20-5452$

View this article at: https://dx.doi.org/10.21037/atm-20-5452

\section{Introduction}

Uncontrolled traumatic hemorrhage is a major cause of preventable death worldwide (1). In 2013, trauma care and the resultant loss of productivity cost approximately $\$ 670$ billion in the USA alone (2). Non-compressible hemorrhage accounts for $90 \%$ of potentially survivable military deaths and $30-40 \%$ of civilian trauma deaths, a statistic that has been unchanged for over 14 years utilizing the current standards of care (3). In military medicine, a recent US Joint Trauma System study reviewed 4,596 US military deaths and identified that 9 out of 10 deaths occurred in the battlefield, prior to admission to a medical facility (4). Even after hospital admission, early mortality is associated with non-compressible hemorrhage (5). Additionally, non-compressible hemorrhage is associated with mortality rates approaching $50 \%$ for patients who require massive blood transfusion or for those who develop a significant coagulopathy (6-8). Coagulopathy affects $25 \%$ of patients with hemorrhage and results from hemodilution, 
hypothermia, and acidosis, among other factors (9). Trauma-induced coagulopathy is defined as a consumptive coagulopathy $(10,11)$. For patients suffering from noncompressible hemorrhage, whether on the battlefield or remote location with limited medical resources, timely resuscitation is critical for survival. With earlier hemorrhage control and patient stabilization, patient outcomes in subsequent definitive care/hospital settings are improved (12).

Non-compressible hemorrhagic injuries can be classified based on their anatomical location. Noncompressible torso hemorrhage (NCTH) is defined as a high-grade injury following trauma to major intrathoracic or intrabdominopelvic organs or vasculature (13). Noncompressible junctional hemorrhage (NCJH) is defined as a high-grade injury present at a point where an extremity meets the torso including the groin above the inguinal ligament, the gluteal region, the axilla, and the base of the neck (14). Non-compressible extremity hemorrhage (NCEH) is defined as a high-grade injury to either the upper or lower extremity vasculature secondary to penetrating injury (15). Injuries are considered high grade or Class III hemorrhage when more than $30 \%$ of a patient's blood volume is lost and clinically present with a systolic blood pressure of less than $90 \mathrm{mmHg}$ (16). Studies have shown NCTH to constitute the largest source of hemorrhage $(67.3 \%)$, followed by junctional (19.2\%) and extremity hemorrhage (13.5\%) (4). Historically, management of NCTH has been the most challenging to control (17).

Several pre-hospital hemostatic techniques and agents are in various stages of development and can be categorized by their mechanism of action, either via mechanical or chemical mechanisms. Mechanical hemostatic agents/ techniques include tourniquets, endovascular aortic occlusion techniques, and passive bioengineered agents which achieve hemostasis through direct pressure, absorptive, or compressive effects. Chemical hemostatic mechanisms include bioengineered agents that achieve hemostasis through supplying hemostatic components with procoagulant, mucoadhesive, or antifibrinolytic properties. Mechanical and chemical hemostatic mechanisms are often used in conjunction with one another.

Resuscitative endovascular balloon occlusion of the aorta (REBOA) (PRYTIME Medical, Boerne, TX, USA) and ResQFoam (Arsenal Medical, Waltham, MA, USA) mechanically achieve hemostasis for NCTH, while XSTAT (REVMEDX, Wilsonville, OR), Tranexamic Acid (TXA), and QuikClot Combat Gauze (QCG) (Z-MEDICA,
Wallingford, CT, USA) chemically achieve hemostasis for NCEH and NCJH. Each of these products represents a novel approach to non-compressible hemorrhage and has recently received or is pursuing U.S. Food and Drug Administration (FDA) approval. Notably, these products have been approved for use by the Committee of Tactical Combat Casualty Care (CoTCCC). Here, we review these various hemostatic agents (Table 1), their structural properties and hemostatic mechanisms, as well as key studies highlighting there in vitro and in vivo efficacy. We present the following article in accordance with the Narrative Review reporting checklist (available at https:// dx.doi.org/10.21037/atm-20-5452). Literature review was conducted by compiling previous case reports, retrospective studies, preclinical studies, and guideline commentaries that were indexed on the PubMed database.

\section{Endovascular aortic occlusive techniques}

The definitive treatment for persistent abdominopelvic hemorrhage centers on endovascular or surgical interventions. In cases of traumatic hemorrhage, when a patient continues to exsanguinate despite various efforts to stop the bleeding, a resuscitative thoracotomy with aortic cross-clamping (RTACC) can be performed to provide temporary hemostasis $(14,18-20)$. Despite the invasive nature of this technique, it is routinely used for hemostasis in trauma patients with a NCTH (21). RTACC for abdominopelvic injury is associated with decreased blood loss, however the thoracotomy itself is not without significant morbidity $(22,23)$. The need for a minimally invasive aortic occlusive technique for NCTH prompted investigation into resuscitative endovascular balloon occlusion of the aorta.

REBOA is an emergency endovascular aortic occlusion technique for patients with NCTH that can be performed in the field and prior to arrival to a hospital setting to minimize blood loss (24). It acts as a temporizing measure to reduce non-compressible abdominal and pelvic hemorrhage, allowing time for definitive surgical and/or endovascular management. Currently, REBOA and RTACC are the two primary aortic occlusion techniques that are utilized in trauma medicine. Compared to RTACC, REBOA is easier, faster, and less invasive. The REBOA technique consists of gaining common femoral arterial (CFA) access, positioning an endovascular balloon within a pre-determined position within the aorta, and inflating the balloon resulting in aortic occlusion (Figure 1) (25). By occluding the descending 
Table 1 Hemostatic agents and techniques

\begin{tabular}{|c|c|c|c|c|c|c|c|c|c|}
\hline $\begin{array}{l}\text { Hemostatic } \\
\text { Agent }\end{array}$ & Description & $\begin{array}{l}\text { Wound site } \\
\text { applications }\end{array}$ & $\begin{array}{l}\text { Administration } \\
\text { route }\end{array}$ & $\begin{array}{l}\text { Instant } \\
\text { control }\end{array}$ & $\begin{array}{l}\text { Effective with } \\
\text { coagulopathies }\end{array}$ & $\begin{array}{l}\text { Easy to } \\
\text { deliver }\end{array}$ & $\begin{array}{l}\text { Easy to } \\
\text { remove }\end{array}$ & $\begin{array}{l}\text { Hemostatic } \\
\text { mechanism }\end{array}$ & $\begin{array}{l}\text { Skill } \\
\text { required }\end{array}$ \\
\hline REBOA & $\begin{array}{l}\text { - Aortic occlusion } \\
\text { device } \\
\text { - Balloon inflation via } \\
\text { flexible catheter }\end{array}$ & $\begin{array}{c}\text { NCTH, lower } \\
\text { extremities }\end{array}$ & $\begin{array}{c}\text { Aortic } \\
\text { occlusion }\end{array}$ & Yes & Yes & No & No & Mechanical & $\begin{array}{c}\text { Trained } \\
\text { physician }\end{array}$ \\
\hline ResQFoam & $\begin{array}{l}\text { - Self expanding } \\
\text { polyurethane foam } \\
\text { - Percutaneous } \\
\text { injection of two liquid } \\
\text { precursors via a } \\
\text { customized trocar }\end{array}$ & $\mathrm{NCTH}$ & $\begin{array}{l}\text { Percutaneous } \\
\text { injection }\end{array}$ & Yes & Yes & Yes & No & Mechanical & $\begin{array}{l}\text { First aid } \\
\text { responder }\end{array}$ \\
\hline $\begin{array}{l}\text { QuikClot } \\
\text { Combat } \\
\text { Gauze }\end{array}$ & $\begin{array}{l}\text { - Non-woven surgical } \\
\text { gauze embedded with } \\
\text { kaolin } \\
\text { - Hemostatic agent }\end{array}$ & $\begin{array}{c}\text { NCTH, NCJH, } \\
\text { NCEH }\end{array}$ & Topical & No & No & Yes & Yes & Chemical & $\begin{array}{l}\text { First aid } \\
\text { responder }\end{array}$ \\
\hline XSTAT & $\begin{array}{l}\text { - Plant-derived } \\
\text { cellulose sponge } \\
\text { pellets coated with } \\
\text { chitosan } \\
\text { - Delivered via a } \\
\text { syringe-like device }\end{array}$ & $\begin{array}{l}\text { NCJH, Deep } \\
\text { Narrow (groin } \\
\text { and axilla } \\
\text { wounds) }\end{array}$ & $\begin{array}{l}\text { Percutaneous } \\
\text { Injection }\end{array}$ & Yes & Yes & Yes & Yes & Chemical & $\begin{array}{l}\text { First aid } \\
\text { responder }\end{array}$ \\
\hline
\end{tabular}

$\mathrm{NCTH}$, non-compressible torso hemorrhage, NCJH, non-compressible junctional hemorrhage; NCEH, non-compressible extremity hemorrhage.

thoracic or abdominal aorta, this technique leads to reduced downstream hemorrhage while augmenting cardiac afterload to support and maintain vital myocardial and cerebral perfusion $(26,27)$. Additionally, partial balloon occlusion or intermittent inflation and deflation of balloon under careful blood pressure monitoring can be performed to reduce risk of downstream ischemia. After completion of the procedure, monitoring for downstream organ and extremity ischemia is necessary.

The REBOA technique divides the aorta into three functional zones. Zone I is located between the left subclavian artery to celiac trunk, zone II is located between the celiac trunk to the lower renal artery and zone III is located between the infrarenal aorta and iliac bifurcation. Occlusion of zone I is optimal for cases of intra-abdominal hemorrhage, ruptured abdominal aortic aneurysm, or other areas of gastrointestinal bleeding. Occlusion of zone
III can be used for control of pelvic hemorrhage when present without abdominal bleeding. Contraindications to the REBOA technique include conditions such as cardiac tamponade and aortic dissection, or in cases of penetrating neck/chest trauma and blunt cardiac/aortic injury where the use of resuscitative thoracotomy is more favorable (25). While REBOA can be lifesaving, it can also lead to major complications; REBOA can result in organ and limb threatening complications including unintended ischemia, pseudoaneurysm, spinal cord injury, lower limb amputation and thrombosis $(24,28,29)$, however these complications must be weighed against the risk of death from exsanguination.

Although the use of REBOA in prehospital settings has been limited, small case series have alluded to the safety and efficacy of this technique. The first successful civilian prehospital aortic occlusion case was reported by Sadek 

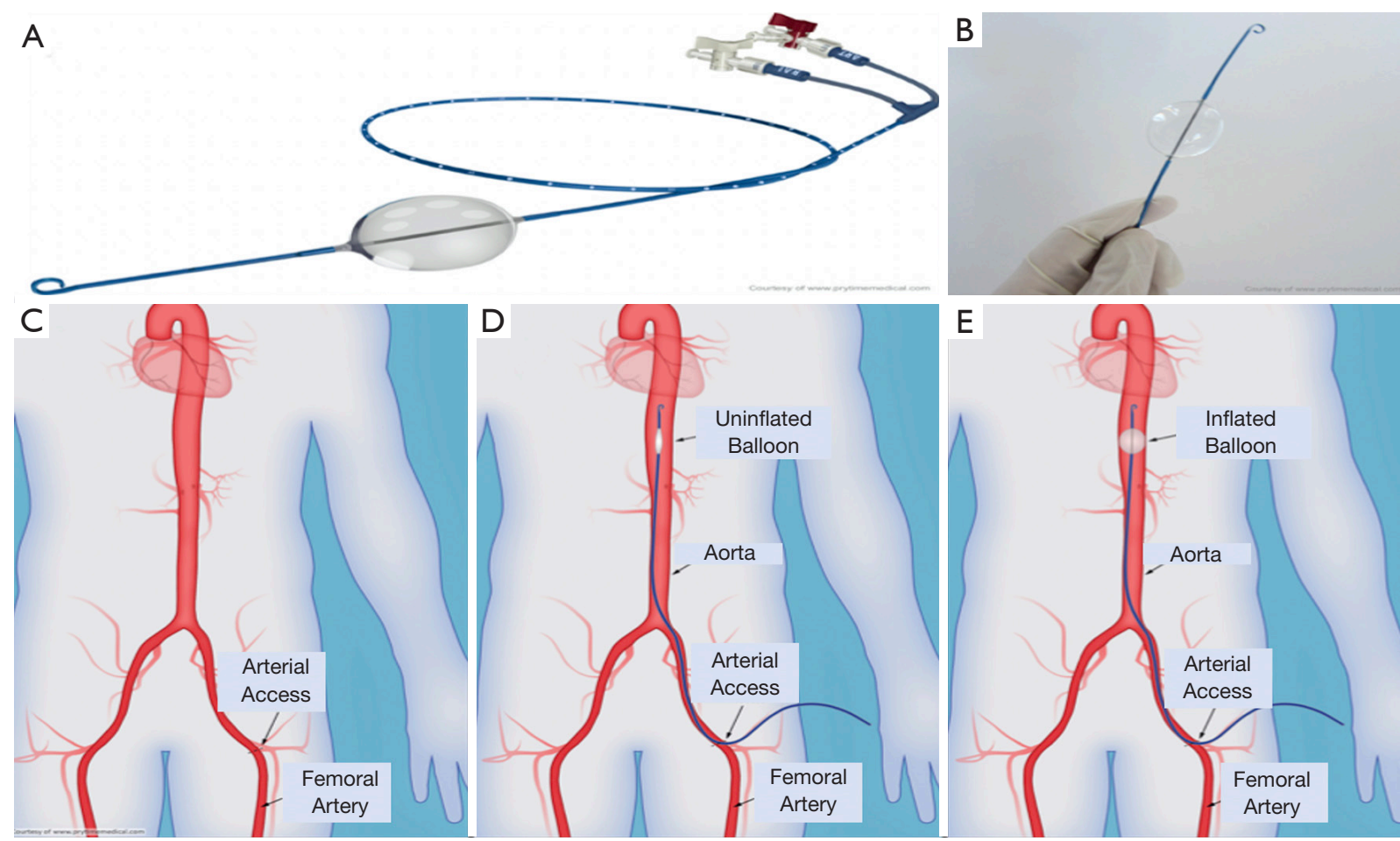

Figure 1 Overview of the REBOA technique. (A) Detailed image of the REBOA catheter and (B) its tip after balloon inflation. (C) Schematic of catheter insertion via the femoral artery, (D) advancement into the abdominal aorta and (E) aortic balloon occlusion. REBOA, resuscitative endovascular balloon occlusion of the aorta.

et al. in 2016 (30). In this case, the patient had a severe pelvic injury following a 15-meter fall with resultant arterial injury and hemodynamic instability, therefore REBOA was performed. The patient was discharged after 52 days without any neurological complications. In the military setting, REBOA has been approved for use in severely injured soldiers where other means of treatment may prove ineffective. Trained field physicians and multidisciplinary teams are able to use REBOA by following Advanced Resuscitative Care (ARC) guidelines. Based on these guidelines, a simplified algorithm for responders is shown in Figure 2. In a case series of injured soldiers, it was shown that 4 patients with torso gunshot or fragmentation wounds, hemoperitoneum, and resulting shock were successfully stabilized using REBOA (30,31). Physiological outcomes are crucial areas of interest to study when determining whether REBOA is a valid approach to control bleeding in NCTH (20). Evidence described by Sambor suggests that REBOA achieves better hemodynamic stability and reduces mortality rates when compared with traditional methods for hemorrhage control such as thoracotomy with aortic crossclamping (20). According to Romagnoli et al., once CFA access is achieved, median time to aortic occlusion with REBOA is 245 seconds while RTACC requires a median of 317 seconds (21). The rate limiting step of REBOA is obtaining CFA access (21). Therefore, expertise in gaining arterial access and availability of ultrasound equipment is critical to its success. Given the complexities associated with occluding the aorta and managing peri-procedural complications, REBOA is typically performed by trained experts.

\section{Topical bioengineered hemostatic agents}

For years, tourniquet usage has been the mainstay of hemorrhage control in the battlefield. However, a number of bioengineered materials have recently emerged that demonstrate great promise (32). The applicability and utility of these agents is determined by the type of injury and location of the bleeding (Table 1). Although tourniquets are used for extremity injuries, bioengineered hemostatic agents can be concurrently used if hemostasis is not initially achieved. Typically, hemostatic agents are utilized for deep wound configurations which present 


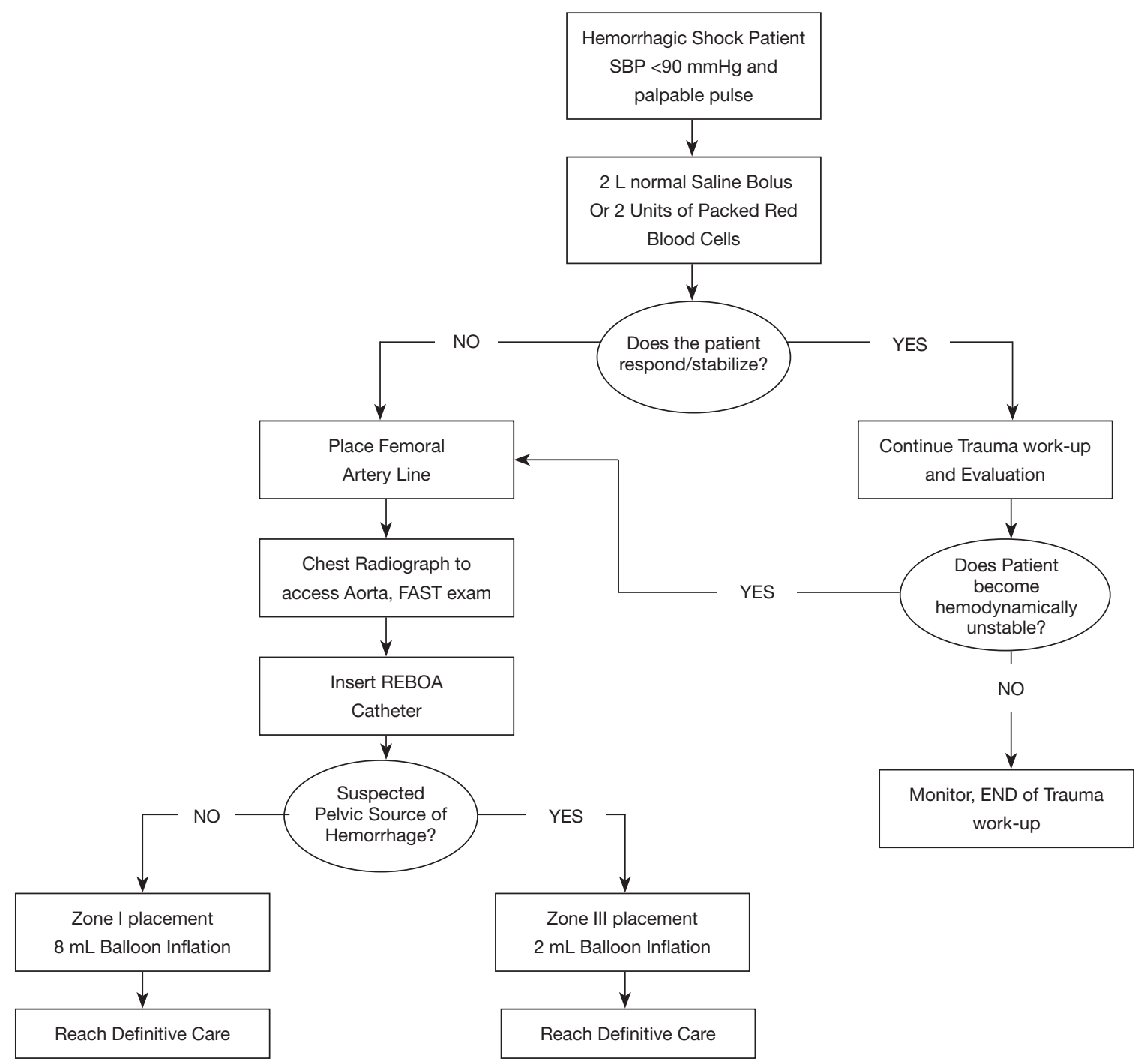

Figure 2 Simplified algorithm for determining occlusion site in the aorta when utilizing the REBOA technique, based on the Advanced Resuscitative Care guidelines. REBOA, resuscitative endovascular balloon occlusion of the aorta.

as gunshot or penetrating injury resulting in noncompressible hemorrhage (33). Topical hemostatic agents are characterized into two main categories: passive and bioactive agents. Passive agents do not chemically interact with the coagulation cascade, but rather promote stasis by providing a scaffold that covers the wound site while working through absorptive and compressive mechanisms. The absorptive characteristics of these materials induces hemostasis through concentrating clotting factors at the site of the injury by rapidly absorbing the water content of blood (12). Conversely, bioactive hemostatic agents activate the coagulation cascade and supply hemostasis stimulating components when activated. Bioactive hemostatic agents can be further categorized into mucoadhesive agents and procoagulants. Mucoadhesive agents, which primarily contain the positively charged polysaccharide chitosan, react with blood and wounded tissue to form an adhesive substance that effectively seals the wound. Procoagulants can either activate the coagulation cascade (Factor XII) or supply clotting factors at the site of injury (12). According to the CoTCCC, these topical hemostatic agents can be used in place of limb and junctional tourniquets if all 3 of the following criteria are met: "the casualty is not in shock; it is possible to monitor the wound closely for bleeding, and 
the tourniquet is not being used to control bleeding from an amputated extremity." (4).

\section{ResQFoam}

ResQFoam is an innovative self-expanding polyurethane foam that acts as a passive topical agent for NCTH. ResQFoam is synthesized through the mixing and percutaneous injection of two liquid precursors: a polyol phase and isocyanate phase via its specialized delivery device (Figure 3). ResQFoam rapidly expands to approximately 35 -fold upon injection into the abdominal cavity via a custom-made trocar (34). The resulting material creates a local tamponade effect, thereby reducing the rate of intra-abdominal hemorrhage while providing wound site coverage and internal compression (Figure 4). Given the complex administration procedure, ResQFoam can only be administered in the field after extensive training (35).

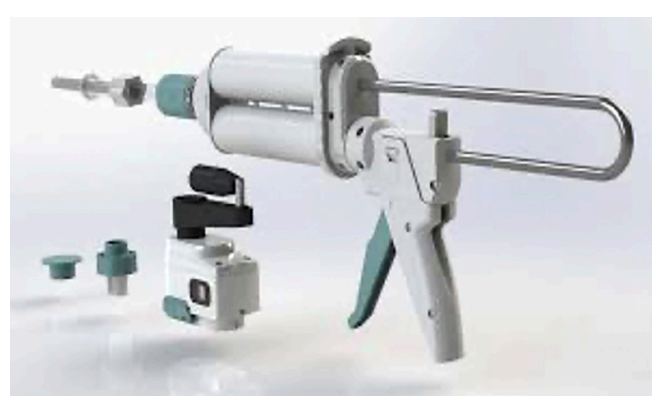

Figure 3 ResQFoam injection device. ResQFoam injection device with two chambers for mixing of the polyol phase and isocyanate phase precursors.
Improper injection may cause serious complications or death if injected into unintended targets such as the aorta or gastrointestinal tract. Removal of the foam upon arrival at the definitive point of care requires laparotomy (36). According to Klein et al., ResQFoam has proven efficacious after 1 year of shelf life and at varying temperatures ranging from 10 to $50{ }^{\circ} \mathrm{C}(37)$.

Several preclinical studies have examined the safety, efficacy, and dosing of ResQFoam. Rago et al. conducted multiple preclinical experiments examining the foams safety profile in various animal hemorrhage models and noted survival benefits for animals receiving the foam when compared to animal groups in which foam was not used. Several complications were noted in these experiments including intestinal pressure necrosis and focal bowel ecchymosis. However, there was no evidence of any adverse toxicity or embolization of foam remnants $(34,38)$. Investigators also studied dosing of ResQFoam, using either $100-\mathrm{mL}$ versus $120-\mathrm{mL}$ formulations. They noticed that the $100-\mathrm{mL}$ dose was significantly faster in hemorrhage control when compared to the $120-\mathrm{mL}$ dose. Foam treatment at both doses resulted in a significant survival benefit and reduction in hemorrhage rate relative to the control group (39). Hence, using a 100-mL dose of ResQFoam proved safe and effective, resulting in an immediate, persistent improvement in mean arterial pressure and a transient increase in intraabdominal pressure. The Wound Stasis System program launched ResQFoam in 2010 and currently ResQFoam is being tested in the REVIVE clinical trial which began in 2019. REVIVE aims to assess the safety, efficacy, and benefit-risk profile of ResQFoam. No update has been published regarding this clinical trial.

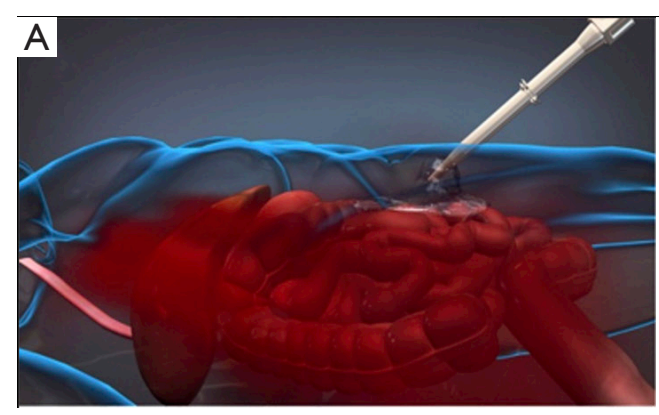

Injury occurs

and ResQFoam

deployed

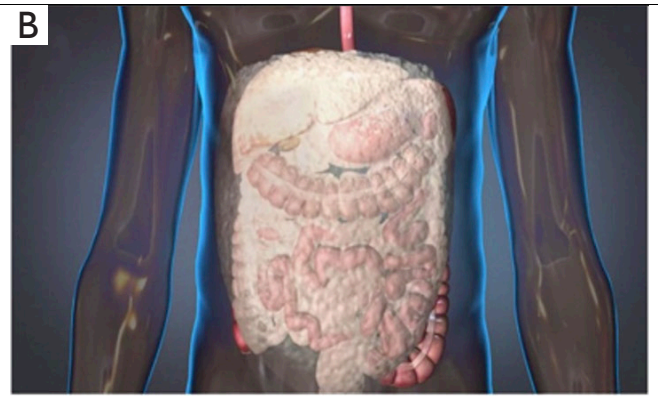

ResQFoam

forms in situ

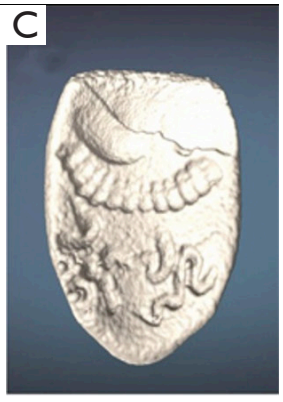

ResQFoam

surgically

extracted

Figure 4 ResQFoam deployment technique. (A) Once injected, the self-expanding foam creates a cast covering the abdominal organs, creating a tamponade effect (B). Schematic of ResQFoam in situ. (C) Image of surgically removed ResQFoam cast. 
A
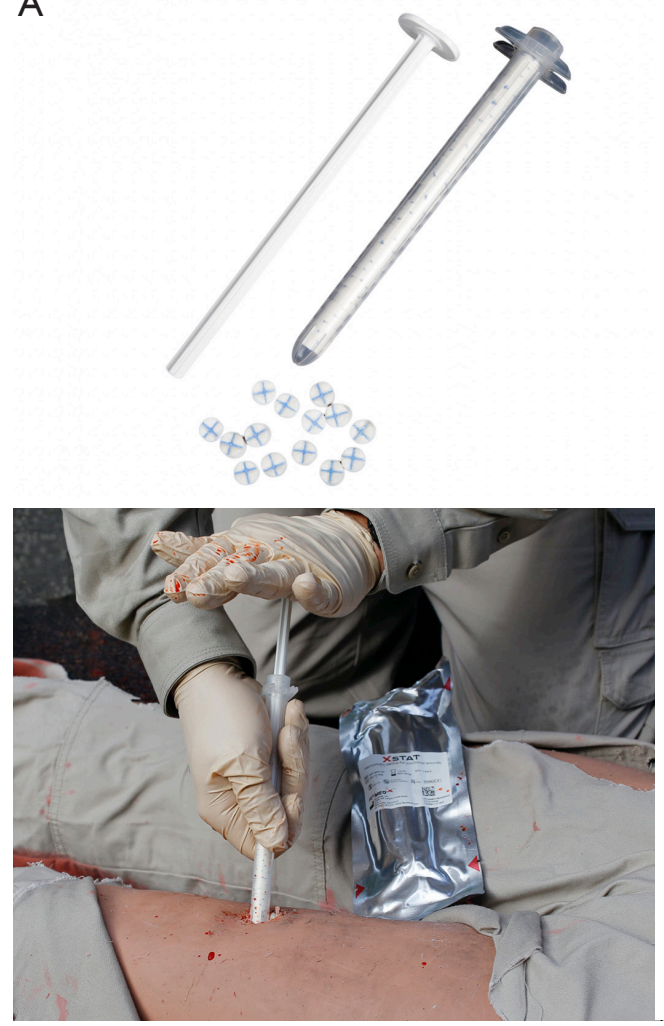

B
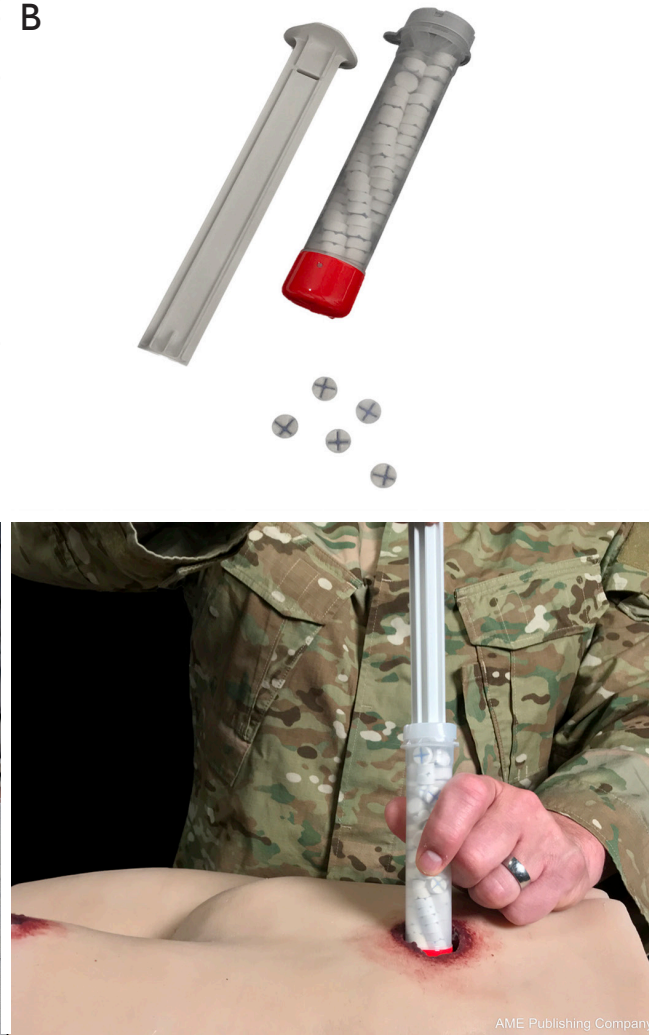

Figure 5 RevMedx XSTAT device with compressive mini-expandable sponges in XSTAT12 and XSTAT30 sizes. (A) XSTAT12 device and demonstration of it being utilized on a mannequin with a narrow, deep tract, non-compressible junctional hemorrhage wound configuration. (B) XSTAT30 device with the device being applied on a mannequin with a wide, deep tract, non-compressible junctional hemorrhage wound configuration.

\section{RevMedx XSTAT}

XSTAT is a bioactive bioengineered agent which uses a chemical hemostatic mechanism composed of plantderived cellulose sponge pellets coated with chitosan that are compressed in a syringe-like device. It combines procoagulant, absorptive, and tamponade properties through its inclusion of chitosan, cellulose, and expansive sponges, respectively. Once the compressed cellulose sponges are delivered to the wound site, the sponges expand axially within 20 seconds (40). These injectable sponges also induce clotting by allowing platelets to settle on the surface of the sponges. The sponges are not biodegradable and must be removed upon definitive care. The sponges are, however, traceable through an embedded radiopaque marker so that any remaining in the body can be easily located on radiography. Currently there are two sizes for the device, marketed as XSTAT12 and XSTAT30 (Figure 5).

XSTAT is intended for use in the battlefield or pre- hospital environments for low- and high-velocity gunshot wounds (deep-tract or narrow-entrance) to the extremities. Its use is contraindicated in the thorax, abdomen, retroperitoneal space, sacral space above the inguinal ligament, and soft tissue above the clavicles. Although XSTAT was initially developed for military trauma, Warriner et al. have described its use in civilian trauma. XSTAT was used in 10 patients with penetrating trauma and hemorrhage was completely stopped on initial deployment in 9 out of 10 cases. Additionally, the use of XSTAT has also been described in non-traumatic hemorrhage, notably in the field of obstetrics as a tamponade agent for postpartum hemorrhage (41).

The efficacy of XSTAT has been tested in standard swine models of lethal junctional hemorrhage, including both femoral and subclavian hemorrhages. It has been shown to significantly decrease mean wound packing time according to a de novo humans factor analysis conducted by the FDA. The efficacy of XSTAT has also been compared to that of 


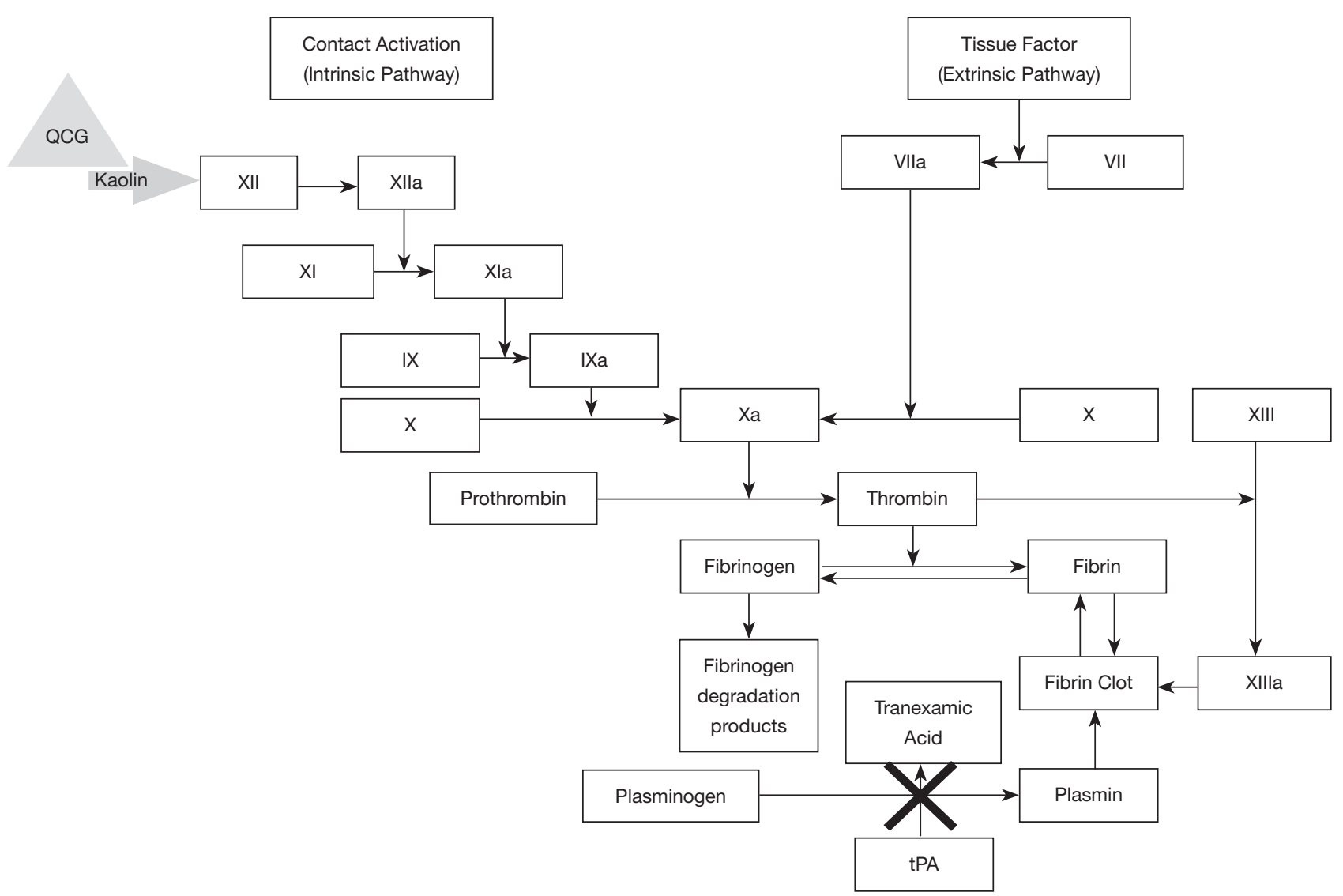

Figure 6 Flow diagram of QuikClot Combat Gauze and Tranexamic Acid mechanism of action on the coagulation cascade. QuikClot Combat Gauze is impregnated with Kaolin, which activates factor XII. Tranexamic Acid is a synthetic lysine analogue that inhibits plasminogen activation. Both agents interfere with the coagulations cascade to ultimately induce hemostasis. REBOA, resuscitative endovascular balloon occlusion of the aorta.

QCG in lethal junctional wounds in coagulopathic swine models. XSTAT was found to be significantly superior in terms of efficiency and speed of hemostasis (42). XSTAT was approved for use by the CoTCCC based upon preclinical results, product ease of use, and its procurement of FDA approval (43-45). Furthermore, no technical device failures or embolic complications were noted $(42,46)$.

\section{TXA}

TXA is a synthetic analogue of lysine and is utilized as an antifibrinolytic drug. TXA affects the coagulation cascade in a myriad of ways, however, it ultimately prevents plasminogen activation (Figure 6). TXA competitively inhibits plasminogen activation to plasmin and noncompetitively inhibits plasmin from breaking down fibrin clots when present at high concentrations (47). Another mechanism of action of TXA involves the blocking of binding of $\alpha-2$ antiplasmin to plasmin, halting plasmin activation. Thus, TXA is a bioactive bioengineered agent which exerts its chemical hemostatic mechanism on the coagulation process by stabilizing formed clots and hindering fibrinolysis. TXA can be administered topically or intravenously. Intravenous administration of TXA was first introduced into clinical practice as a means for bleeding disorder management.

The first clinical trial to show a reduction in mortality in trauma patients was the Clinical Randomization of an Antifibrinolytic in Significant Hemorrhage trial (CRASH-2) in 2010. However, the use of intravenous TXA in prehospital and combat settings was not approved by the CoTCCC until 2012, when the Military Application of TXA in Trauma Emergency Resuscitation (MATTERs) data was published (48-50). MATTERs reported the experience of using intravenous TXA in the combat setting 
and characterized its effect on measures of coagulopathy and survival following wartime injury. One study demonstrated that intravenous administration of TXA resulted in a decrease in mortality by $17.4-23.9 \%$ in trauma settings $(48,51)$. Additionally, numerous studies published data in support of intravenous TXA administration in prehospital and combat settings (52-55).

The CoTCCC guidelines recommend that any patient with significant hemorrhage resulting in abnormal vital signs or any patient at risk for significant hemorrhage, such as a pelvic fracture or evidence of intraabdominal bleeding, be given a loading dose of 1 gram of TXA, followed by 1 gram infusion over 8 hours, within a 3 -hour window period after traumatic injury. A systematic review conducted by Picetti et al. determined that a minimal concentration of $5 \mathrm{mg} / \mathrm{L}$ TXA in the blood had an antifibrinolytic effect (56). Conversely, TXA administered after three hours was demonstrated to be less effective and potentially harmful (57), as TXAs efficacy is directly tied to its administration time (58).

Recent data has shown topical TXA to be just as efficacious in reducing surgical bleeding as intravenous administration (59). Additionally, topical administration has less systemic absorption, therefore the direct application of tranexamic acid to the bleeding site could potentially reduce bleeding with minimal side effects (60). Although topical TXA usage is common in clinical settings such as orthopedic and cardiothoracic surgery (61), its use in trauma and combat setting has been limited to date. A preclinical study conducted by Baylis et al. used a wound dressing created by calcium carbonate microparticles loaded with thrombin/TXA and found it to be an effective means of achieving hemostasis. All of the animals in this study treated with the dressing survived and maintained lower serum lactate and higher hemoglobin concentrations compared to animals treated with a dressing lacking TXA (62). This preliminary study demonstrated the promise of topical TXA dressings in point of care hemorrhage control. Further research into dosing regimens and risk of adverse effects, however, is still needed $(63,64)$.

\section{QCG}

QCG is a non-woven surgical gauze embedded with kaolin for external wound treatment. Kaolin directly activates factor XII leading to prompt activation of the coagulation cascade (Figure 6) (65). QCG is therefore a bioactive bioengineered agent that uses a chemical hemostatic mechanism. QCG remains at the wound site for up to 24 hours until further medical care can be provided. Of note, QCG is different in its production and hemostatic mechanism than the first generation hemostatic, QuikClot (QC) manufactured by the same company. This first-generation agent was a zeolite-based material but was discontinued in 2008 due to concerns of exothermic reactions resulting in adjacent tissue damage at the time of application $(66,67)$. QCG was approved by FDA for external application in $2013(68,69)$. CoTCCC recommends using QCG by placing it on or into wounds, followed by at least 3 minutes of direct pressure. During this time, junctional tourniquets should be applied to sites amenable to their use.

QC was initially studied extensively in porcine models $(65,70,71)$. When assessing lethal femoral injury in porcine models, QC was shown to control bleeding more effectively than standard packing, while maintaining this control in the setting of movement $(70,71)$. Despite these benefits, it was discontinued due to the previously mentioned exothermic reactions. Subsequent studies by Gegel et al. examined the efficacy of its successor QCG. The investigators noted no adverse side effects like the ones associated with first generation QC, however concluded that there was not enough high-level data available on trauma outcomes to support its current use, although the initial results appeared promising (66).

Although there have been no prospective trials for QCG to date, preliminary case reports of QCG have shown that it can be effective for the prehospital treatment of combat casualties (72). The largest case series of QCG included 122 patients in prehospital treatment by the Israel Defense Forces Medical Groups. In this series, there was an $88.6 \%$ selfreported success rate in halting junctional hemorrhage (73). Another case series of QCG use reported a 79\% success rate in the arrest of hemorrhage with no adverse effects observed. Failures were noted in the neck, buttock, and thigh, where there was large soft tissue injury with major vascular compromise (12). QCG is currently used on the battlefield and in prehospital injuries and is administered by medics as well as advanced life support (ALS) providers in Israel (73). The CoTCCC endorsed QCG usage for all military personal in 2015 (74). CoTCCC also recommended QCG as the firstline hemostatic agent for life-threatening bleeding that is not controllable by tourniquet placement (69).

\section{Agent selection}

Early hemorrhage control is critical for good patient outcomes. Timely use of temporary hemostatic measures, wound 


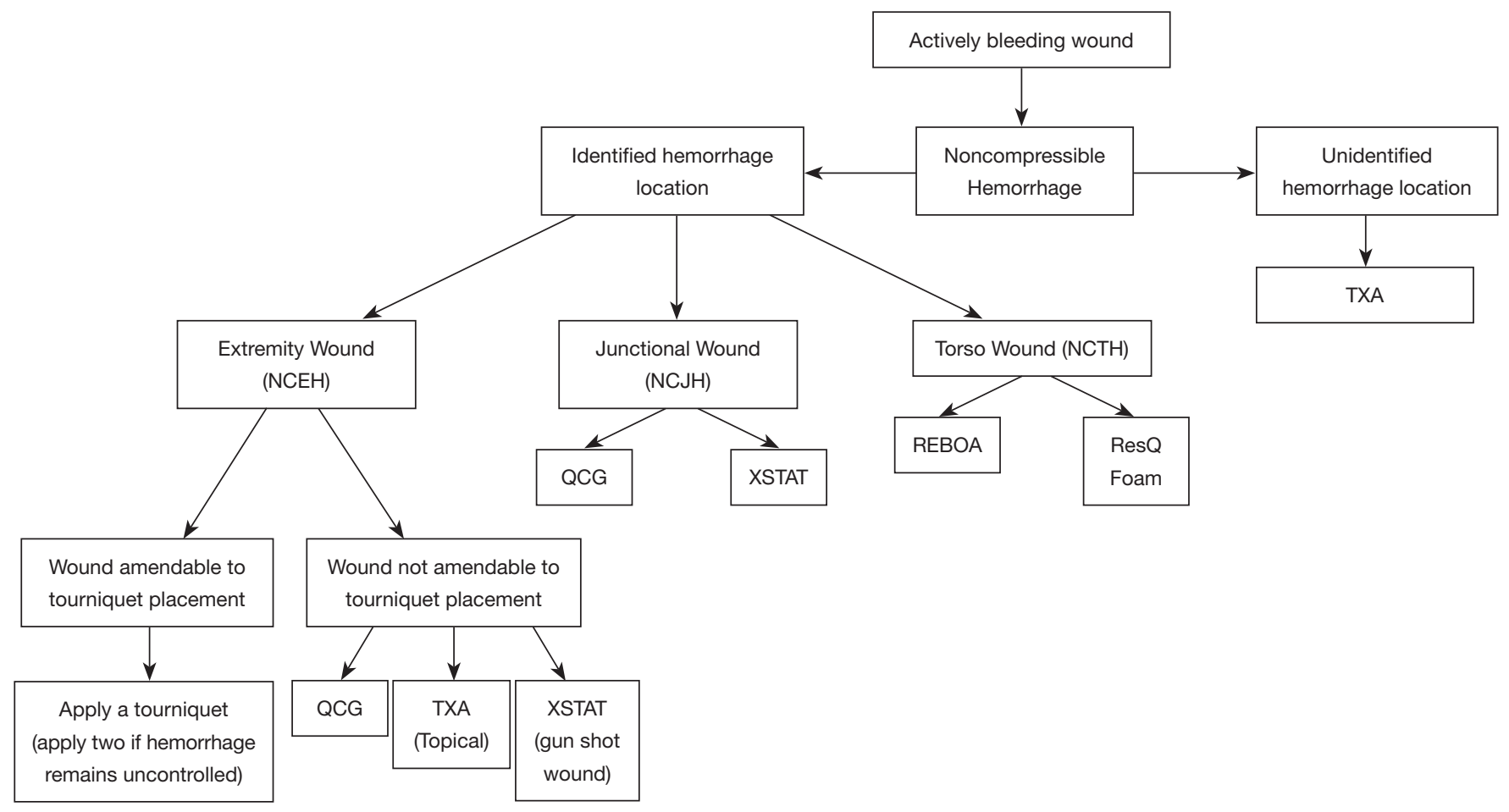

Figure 7 Simplified Algorithm for hemostatic agent selection based on wound site and Tactical Combat Casualty Care recommendations. REBOA, resuscitative endovascular balloon occlusion of the aorta.

configuration and location, and mechanism of injury are all factors that must be considered when selecting a hemostatic agent. Operator training and experience in using each agent is essential as well, as some techniques such as REBOA require physician-level training. Other agents including TXA, ResQFoam, QCG, and XSTAT can be administered by first responders or even bystanders with a basic level of training. Based on wound location, a simplified algorithm to guide responders for agent selection is shown in Figure 7.

\section{Emerging bioengineered approaches}

In recent years, nanotechnology has been utilized to further develop next generation hemostatic agents (75). Behnke et al. were among the first to conduct preclinical experiments using nanotechnology as a hemostatic agent. They designed a self-assembling peptide that establishes a nanofiber barrier to achieve hemostasis for internal bleeds. The investigators used multiple mammalian organ models for the experiment including the brain, spinal cord, femoral artery, liver, and skin. Additionally, they performed experiments characterizing the nanofiber barrier. In this study, the nanofiber barrier was able to achieve complete hemostasis for internal bleeds in less than 15 seconds in all experimental models. They characterized the nanofiber barrier as nontoxic and nonimmunogenic.

Recently, Meddahi-Pellé et al. found that bleeding control and tissue repair can be achieved through the process of nano-bridging. The concept of nano-bridging starts with the droplet of a nanoparticle solution being spread over the wound surface of a tissue. The nanoparticle solution includes silica and iron oxide nanoparticles. Once the solution is applied, manual pressure approximates the wound edges and initiates the process of adhesion. The results of this study demonstrated wound closure and induced hemostasis after just one minute (76). Although strong adhesion and temporary hemostasis were demonstrated, no data has been published regarding the safety and biocompatibility profile of this potential therapy. Multiple preclinical studies have recently been published $(76,77)$ and demonstrate intriguing results with the potential for the integration of nanotechnology into hemorrhage control.

\section{Conclusions}

Non-compressible hemorrhage remains a leading cause of 
pre-hospital morbidity and mortality. In recent years, several hemostatic agents and techniques have been developed to address this problem. The ideal hemostatic agent or technique should be safe, efficacious, easily administered, biocompatible, and bacteriostatic. REBOA is intended as a temporizing measure to control non-compressible abdominal and pelvic hemorrhage as a bridge to definitive surgical or endovascular management. The four topical bioengineered hemostatic agents previously discussed differ in many aspects, most importantly their materials, targeted application site, and hemostatic mechanism. Based on the literature reviewed none of the current hemostatic products meet all the criteria for an ideal hemostatic agent or device. Nevertheless, they have demonstrated efficacy in controlling pre-hospital hemorrhage and could be used as a last resort to increase patient survival rates. Emerging technologies including nanotechnology have demonstrated great initial promise for creating more ideal temporizing hemostatic agents. Although a lack of prospective data limits determination of efficacy, published case series support the use of these agents when definitive treatment cannot be delivered promptly.

\section{Acknowledgments}

Funding: None.

\section{Footnote}

Provenance and Peer Review: This article was commissioned by the editorial office, Annals of Translational Medicine for the series "Endovascular interventions in trauma". The article has undergone external peer review.

Reporting Checklist: The authors have completed the Narrative Review reporting checklist. Available at https:// dx.doi.org/10.21037/atm-20-5452

Conflicts of Interest: All authors have completed the ICMJE uniform disclosure form (available at https://dx.doi. org/10.21037/atm-20-5452). The series "Endovascular interventions in trauma" was commissioned by the editorial office without any funding or sponsorship. KQ served as the unpaid Guest Editor of the series and serves as an unpaid editorial board member of Annals of Translational Medicine from Aug 2019 to Jul 2021. RO serves as an unpaid editorial board member of Annals of Translational Medicine from Aug 2019 to Jul 2021. The other authors have no conflicts of interest to declare.

Ethical Statement: The authors are accountable for all aspects of the work in ensuring that questions related to the accuracy or integrity of any part of the work are appropriately investigated and resolved.

Open Access Statement: This is an Open Access article distributed in accordance with the Creative Commons Attribution-NonCommercial-NoDerivs 4.0 International License (CC BY-NC-ND 4.0), which permits the noncommercial replication and distribution of the article with the strict proviso that no changes or edits are made and the original work is properly cited (including links to both the formal publication through the relevant DOI and the license). See: https://creativecommons.org/licenses/by-nc-nd/4.0/.

\section{References}

1. Behrens AM, Sikorski MJ, Kofinas P. Hemostatic strategies for traumatic and surgical bleeding. J Biomed Mater Res A 2014;102:4182-94.

2. Berwick DM, Downey AS, Cornett EA. A National Trauma Care System to Achieve Zero Preventable Deaths After Injury: Recommendations From a National Academies of Sciences, Engineering, and Medicine Report. JAMA 2016;316:927-8.

3. Aberle SJ, Dennis AJ, Landry JM, et al. Hemorrhage control by law enforcement personnel: a survey of knowledge translation from the military combat experience. Mil Med 2015;180:615-20.

4. Eastridge BJ, Mabry RL, Seguin P, et al. Death on the battlefield (2001-2011): implications for the future of combat casualty care. J Trauma Acute Care Surg 2012;73:S431-7.

5. Bardes JM, Inaba K, Schellenberg M, et al. The contemporary timing of trauma deaths. J Trauma Acute Care Surg 2018;84:893-9.

6. Curry N, Hopewell S, Dorée C, et al. The acute management of trauma hemorrhage: a systematic review of randomized controlled trials. Crit Care 2011;15:R92.

7. Frith D, Goslings JC, Gaarder C, et al. Definition and drivers of acute traumatic coagulopathy: clinical and experimental investigations. J Thromb Haemost 2010;8:1919-25.

8. Brohi K, Singh J, Heron M, et al. Acute traumatic coagulopathy. J Trauma 2003;54:1127-30.

9. Kauvar DS, Lefering R, Wade CE. Impact of hemorrhage 
on trauma outcome: an overview of epidemiology, clinical presentations, and therapeutic considerations. J Trauma 2006;60:S3-11.

10. Caspers M, Maegele M, Fröhlich M. Current strategies for hemostatic control in acute trauma hemorrhage and trauma-induced coagulopathy. Expert Rev Hematol 2018;11:987-95.

11. Noel P, Cashen S, Patel B. Trauma-induced coagulopathy: from biology to therapy. Semin Hematol 2013;50:259-69.

12. Allison HA. Hemorrhage Control: Lessons Learned From the Battlefield Use of Hemostatic Agents That Can Be Applied in a Hospital Setting. Crit Care Nurs Q 2019;42:165-72.

13. Morrison JJ. Noncompressible Torso Hemorrhage. Crit Care Clin 2017;33:37-54.

14. Donley ER, Loyd JW. Hemorrhage Control. 2020. In: StatPearls [Internet]. Treasure Island (FL): StatPearls Publishing, 2021.

15. Richard Slama MJ. The Emergency Medicine Trauma Handbook. Cambridge University Press: Cambridge University Press, 2019.

16. Morrison JJ, Rasmussen TE. Noncompressible torso hemorrhage: a review with contemporary definitions and management strategies. Surg Clin North Am 2012;92:84358, vii.

17. van Oostendorp SE, Tan EC, Geeraedts LM Jr. Prehospital control of life-threatening truncal and junctional haemorrhage is the ultimate challenge in optimizing trauma care; a review of treatment options and their applicability in the civilian trauma setting. Scand J Trauma Resusc Emerg Med 2016;24:110.

18. Kragh JF Jr, Murphy C, Dubick MA, et al. New tourniquet device concepts for battlefield hemorrhage control. US Army Med Dep J 2011;38-48.

19. Ribeiro Junior MAF, Feng CYD, Nguyen ATM, et al. The complications associated with Resuscitative Endovascular Balloon Occlusion of the Aorta (REBOA). World J Emerg Surg 2018;13:20.

20. Sambor M. Resuscitative Endovascular Balloon Occlusion of the Aorta for Hemorrhage Control in Trauma Patients: An Evidence-Based Review. J Trauma Nurs 2018;25:33-7.

21. Romagnoli A, Teeter W, Pasley J, et al. Time to aortic occlusion: It's all about access. J Trauma Acute Care Surg 2017;83:1161-4.

22. Ledgerwood AM, Kazmers M, Lucas CE. The role of thoracic aortic occlusion for massive hemoperitoneum. J Trauma 1976;16:610-5.

23. Rhee PM, Acosta J, Bridgeman A, et al. Survival after emergency department thoracotomy: review of published data from the past 25 years. J Am Coll Surg 2000;190:288-98.

24. Bulger EM, Perina DG, Qasim Z, et al. Clinical use of resuscitative endovascular balloon occlusion of the aorta (REBOA) in civilian trauma systems in the USA, 2019: a joint statement from the American College of Surgeons Committee on Trauma, the American College of Emergency Physicians, the National Association of Emergency Medical Services Physicians and the National Association of Emergency Medical Technicians. Trauma Surg Acute Care Open 2019;4:e000376.

25. Stannard A, Eliason JL, Rasmussen TE. Resuscitative endovascular balloon occlusion of the aorta (REBOA) as an adjunct for hemorrhagic shock. J Trauma 2011;71:1869-72.

26. White JM, Cannon JW, Stannard A, et al. Endovascular balloon occlusion of the aorta is superior to resuscitative thoracotomy with aortic clamping in a porcine model of hemorrhagic shock. Surgery 2011;150:400-9.

27. Markov NP, Percival TJ, Morrison JJ, et al. Physiologic tolerance of descending thoracic aortic balloon occlusion in a swine model of hemorrhagic shock. Surgery 2013;153:848-56.

28. Davidson AJ, Russo RM, Reva VA, et al. The pitfalls of resuscitative endovascular balloon occlusion of the aorta: Risk factors and mitigation strategies. J Trauma Acute Care Surg 2018;84:192-202.

29. Joseph B, Zeeshan M, Sakran JV, et al. Nationwide Analysis of Resuscitative Endovascular Balloon Occlusion of the Aorta in Civilian Trauma. JAMA Surg 2019;154:500-8.

30. Sadek S, Lockey DJ, Lendrum RA, et al. Resuscitative endovascular balloon occlusion of the aorta (REBOA) in the pre-hospital setting: An additional resuscitation option for uncontrolled catastrophic haemorrhage. Resuscitation 2016;107:135-8.

31. Manley JD, Mitchell BJ, DuBose JJ, et al. A Modern Case Series of Resuscitative Endovascular Balloon Occlusion of the Aorta (REBOA) in an Out-of-Hospital, Combat Casualty Care Setting. J Spec Oper Med Spring;17:1-8.

32. Littlejohn L, Bennett BL, Drew B. Application of current hemorrhage control techniques for backcountry care: part two, hemostatic dressings and other adjuncts. Wilderness Environ Med 2015;26:246-54.

33. Güven HE. Topical hemostatics for bleeding control in pre-hospital setting: Then and now. Ulus Travma Acil Cerrahi Derg 2017;23:357-61.

34. Chang JC, Holloway BC, Zamisch M, et al. ResQFoam for the Treatment of Non-Compressible Hemorrhage on the Front Line. Mil Med 2015;180:932-3. 
35. Rago AP, Sharma U, Sims K, et al. Conceptualized Use of Self-Expanding Foam to Rescue Special Operators From Abdominal Exsanguination: Percutaneous Damage Control for the Forward Deployed. J Spec Oper Med 2015;15:39-45.

36. Chaudery M, Clark J, Wilson MH, et al. Traumatic intraabdominal hemorrhage control: has current technology tipped the balance toward a role for prehospital intervention? J Trauma Acute Care Surg 2015;78:153-63.

37. Klein MK, Tsihlis ND, Pritts TA, et al. Emerging Therapies for Prehospital Control of Hemorrhage. J Surg Res 2020;248:182-90.

38. Rago AP, Duggan MJ, Beagle J, et al. Self-expanding foam for prehospital treatment of intra-abdominal hemorrhage: 28-day survival and safety. J Trauma Acute Care Surg 2014;77:S127-33.

39. Rago A, Duggan MJ, Marini J, et al. Self-expanding foam improves survival following a lethal, exsanguinating iliac artery injury. J Trauma Acute Care Surg 2014;77:73-7.

40. Mueller GR, Pineda TJ, Xie HX, et al. A novel spongebased wound stasis dressing to treat lethal noncompressible hemorrhage. J Trauma Acute Care Surg 2012;73:S134-9.

41. Rodriguez MI, Jensen JT, Gregory K, et al. A novel tamponade agent for management of post partum hemorrhage: adaptation of the Xstat mini-sponge applicator for obstetric use. BMC Pregnancy Childbirth 2017;17:187.

42. Rall JM, Cox JM, Songer AG, et al. Comparison of novel hemostatic dressings with QuikClot combat gauze in a standardized swine model of uncontrolled hemorrhage. J Trauma Acute Care Surg 2013;75:S150-6.

43. Satterly S, Nelson D, Zwintscher N, et al. Hemostasis in a noncompressible hemorrhage model: an end-user evaluation of hemostatic agents in a proximal arterial injury. J Surg Educ 2013;70:206-11.

44. Kragh JF Jr, Aden JK, Steinbaugh J, et al. Gauze vs XSTAT in wound packing for hemorrhage control. Am J Emerg Med 2015;33:974-6.

45. Sims K, Montgomery HR, Dituro P, et al. Management of External Hemorrhage in Tactical Combat Casualty Care: The Adjunctive Use of XStat ${ }^{\mathrm{TM}}$ Compressed Hemostatic Sponges: TCCC Guidelines Change 15-03. J Spec Oper Med 2016;16:19-28.

46. Warriner Z, Lam L, Matsushima K, et al. Initial evaluation of the efficacy and safety of in-hospital expandable hemostatic minisponge use in penetrating trauma. J Trauma Acute Care Surg 2019;86:424-30.

47. Sharma V, Fan J, Jerath A, et al. Pharmacokinetics of tranexamic acid in patients undergoing cardiac surgery with use of cardiopulmonary bypass. Anaesthesia 2012;67:1242-50.

48. Huebner BR, Dorlac WC, Cribari C. Tranexamic Acid Use in Prehospital Uncontrolled Hemorrhage. Wilderness Environ Med 2017;28:S50-60.

49. Williams-Johnson JA, McDonald AH, Strachan GG, et al. Effects of tranexamic acid on death, vascular occlusive events, and blood transfusion in trauma patients with significant haemorrhage (CRASH-2) A randomised, placebo-controlled trial. West Indian Med J 2010;59:612-24.

50. Morrison JJ, Dubose JJ, Rasmussen TE, et al. Military Application of Tranexamic Acid in Trauma Emergency Resuscitation (MATTERs) Study. Arch Surg 2012;147:113-9.

51. Peng Z, Ban K, LeBlanc A, et al. Intraluminal tranexamic acid inhibits intestinal sheddases and mitigates gut and lung injury and inflammation in a rodent model of hemorrhagic shock. J Trauma Acute Care Surg 2016;81:358-65.

52. Heier HE, Badloe J, Bohonek M, et al. Use of Tranexamic Acid in Bleeding Combat Casualties. Mil Med 2015;180:844-6.

53. Lipsky AM, Abramovich A, Nadler R, et al. Tranexamic acid in the prehospital setting: Israel Defense Forces' initial experience. Injury 2014;45:66-70.

54. Wright C. Battlefield administration of tranexamic acid by combat troops: a feasibility analysis. J R Army Med Corps 2014;160:271-2.

55. Aedo-Martín D, García-Cañas R, Navarro-Suay R, et al. Use of tranexamic acid in combat casualties. Experience of the Spanish medical corps. Clinical series and literature review. Rev Esp Cir Ortop Traumatol 2016;60:200-5.

56. Picetti R, Shakur-Still H, Medcalf RL, et al. What concentration of tranexamic acid is needed to inhibit fibrinolysis? A systematic review of pharmacodynamics studies. Blood Coagul Fibrinolysis 2019;30:1-10.

57. Stansfield R, Morris D, Jesulola E. The Use of Tranexamic Acid (TXA) for the Management of Hemorrhage in Trauma Patients in the Prehospital Environment: Literature Review and Descriptive Analysis of Principal Themes. Shock 2020;53:277-83.

58. Roberts I, Perel P, Prieto-Merino D, et al. Effect of tranexamic acid on mortality in patients with traumatic bleeding: prespecified analysis of data from randomised controlled trial. BMJ 2012;345:e5839.

59. Ker K, Beecher D, Roberts I. Topical application of tranexamic acid for the reduction of bleeding. Cochrane Database Syst Rev 2013;CD010562. 
60. Ausen K, Pleym H, Liu J, et al. Serum Concentrations and Pharmacokinetics of Tranexamic Acid after Two Means of Topical Administration in Massive Weight Loss Skin-Reducing Surgery. Plast Reconstr Surg 2019;143:1169e-78e.

61. Montroy J, Hutton B, Moodley P, et al. The efficacy and safety of topical tranexamic acid: A systematic review and meta-analysis. Transfus Med Rev 2018. [Epub ahead of print]. doi: 10.1016/j.tmrv.2018.02.003.

62. Baylis JR, St John AE, Wang X, et al. Self-Propelled Dressings Containing Thrombin and Tranexamic Acid Improve Short-Term Survival in a Swine Model of Lethal Junctional Hemorrhage. Shock 2016;46:123-8.

63. Tuttle JR, Feltman PR, Ritterman SA, et al. Effects of Tranexamic Acid Cytotoxicity on In Vitro Chondrocytes. Am J Orthop (Belle Mead NJ) 2015;44:E497-502.

64. Xu R, Shi D, Ge W, et al. Quantitative efficacy of topical administration of tranexamic acid on postoperative bleeding in total knee arthroplasty. Br J Clin Pharmacol 2017;83:2485-93.

65. Kheirabadi BS, Edens JW, Terrazas IB, et al. Comparison of new hemostatic granules/powders with currently deployed hemostatic products in a lethal model of extremity arterial hemorrhage in swine. J Trauma 2009;66:316-26; discussion 327-8.

66. Gegel BT, Austin PN, Johnson AD. An evidence-based review of the use of a combat gauze (QuikClot) for hemorrhage control. AANA J 2013;81:453-8.

67. Basadonna G. QuikClot combat gauze for hemorrhage control. Prehosp Disaster Med 2012;27:217.

68. Sena MJ, Douglas G, Gerlach T, et al. A pilot study of the use of kaolin-impregnated gauze (Combat Gauze) for packing high-grade hepatic injuries in a hypothermic

Cite this article as: Jamal L, Saini A, Quencer K, Altun I, Albadawi H, Khurana A, Naidu S, Patel I, Alzubaidi S, Oklu R. Emerging approaches to pre-hospital hemorrhage control: a narrative review. Ann Transl Med 2021;9(14):1192. doi: 10.21037/atm-20-5452 coagulopathic swine model. J Surg Res 2013;183:704-9.

69. Pourshahrestani S, Zeimaran E, Djordjevic I, et al. Inorganic hemostats: The state-of-the-art and recent advances. Mater Sci Eng C Mater Biol Appl 2016;58:1255-68.

70. Garcia-Blanco J, Gegel B, Burgert J, et al. The Effects of Movement on Hemorrhage When QuikClot ${ }^{\circledR}$ Combat Gauze $^{\mathrm{TM}}$ Is Used in a Hypothermic Hemodiluted Porcine Model. J Spec Oper Med 2015;15:57-60.

71. Johnson D, Westbrook DM, Phelps D, et al. The effects of QuikClot Combat Gauze on hemorrhage control when used in a porcine model of lethal femoral injury. Am J Disaster Med 2014;9:309-15.

72. Ran Y, Hadad E, Daher S, et al. QuikClot Combat Gauze use for hemorrhage control in military trauma: January 2009 Israel Defense Force experience in the Gaza Strip-a preliminary report of 14 cases. Prehosp Disaster Med 2010;25:584-8.

73. Shina A, Lipsky AM, Nadler R, et al. Prehospital use of hemostatic dressings by the Israel Defense Forces Medical Corps: A case series of 122 patients. J Trauma Acute Care Surg 2015;79:S204-9.

74. Bennett BL. Bleeding Control Using Hemostatic Dressings: Lessons Learned. Wilderness Environ Med 2017;28:S39-49.

75. Ellis-Behnke RG, Liang YX, Tay DK, et al. Nano hemostat solution: immediate hemostasis at the nanoscale. Nanomedicine 2006;2:207-15.

76. Gaston E, Fraser JF, Xu ZP, et al. Nano- and micromaterials in the treatment of internal bleeding and uncontrolled hemorrhage. Nanomedicine 2018;14:507-19.

77. Hangge $\mathrm{P}$, Stone J, Albadawi H, et al. Hemostasis and nanotechnology. Cardiovasc Diagn Ther 2017;7:S267-75. 